\title{
A Quantitative Analysis Model Established to Determine the Concentration of Each Source in Mixed Astaxanthin from Different Sources
}

\author{
Xiping Du ${ }^{1,2,3,4}$, Xin Wang ${ }^{1}$, Manli Bai ${ }^{1}$, Shaosong Liu ${ }^{5}$, Gaoling Huang ${ }^{1,2,3,4}$, Qin Zhang ${ }^{1, *}$, \\ Hui Ni ${ }^{1,2,3,4}$ and Feng Chen ${ }^{6}$ \\ 1 College of Food and Biological Engineering, Jimei University, Xiamen 361021, Fujian, China; \\ xipingdu@jmu.edu.cn (X.D.); xinwang714@163.com (X.W.); manliact@163.com (M.B.); \\ hgaol@jmu.edu.cn (G.H.); nihui@jmu.edu.cn (H.N.) \\ 2 Fujian Provincial Key Laboratory of Food Microbiology and Enzyme Engineering, Xiamen 361021, \\ Fujian, China \\ 3 Research Center of Food Biotechnology of Xiamen City, Xiamen 361021, Fujian, China \\ 4 Key Laboratory of Systemic Utilization and In-depth Processing of Economic Seaweed, Xiamen Southern \\ Ocean Technology Center of China, Xiamen 361021, Fujian, China \\ 5 Plant Introduction \& Quarantine and Plant Product Key Laboratory of Xiamen City, Xiamen Overseas \\ Chinese Subtropical Plant Introduction Garden, Xiamen 361002, Fujian, China; 1ss0001888@163.com \\ 6 Department of Food, Nutrition and Packaging Sciences, Clemson University, Clemson, SC 29634, USA; \\ Fchen@Clemson.edu \\ * Correspondence: qinzhang@jmu.edu.cn; Tel.: +861-596-081-0583
}

Received: 30 December 2019; Accepted: 27 January 2020; Published: 31 January 2020

\begin{abstract}
Astaxanthin from different sources possesses different biological activities and optical isomers. The ingredients of astaxanthin mixtures from different sources on the market have often been mislabeled. Therefore, it is important to determine the sources of astaxanthin and their respective concentrations in a mixture. To solve this problem, a quantitative analysis model was established and further verified. The results showed that the deviation between the calculated concentration and the actual concentration ranged from 0 to $7 \mu \mathrm{g} / \mathrm{mL}$, and the recovery rate was between $88.90 \%$ and $103.56 \%$. This indicates that the quantitative analysis model of astaxanthin was feasible and reliable. This study not only has important applications in the astaxanthin mixture component determination but may also shed light on the quantitative analysis of other sample mixtures with stereoisomers from different sources.
\end{abstract}

Keywords: quantitative analysis model; stereoisomers; establishment; astaxanthin; verification

\section{Introduction}

Astaxanthin ( $3,3^{\prime}$-dihydroxy- $\beta, \beta^{\prime}$-carotene- $4,4^{\prime}$-dione), which is a ketocarotenoid oxidized from $\beta$-carotene [1,2], primarily comes from Phaffia rhodozyma, Haematococcus pluvialis, and chemical synthesis. Due to the presence of conjugated double bonds and $\alpha$-hydroxyketones in its structure, astaxanthin has the strongest antioxidant activity among identified chemicals to date [3] and is called a 'super antioxidant.' The antioxidant capacity of astaxanthin is 500 times that of vitamin $\mathrm{E}$ and 10 times that of $\beta$-carotene $[4,5]$. Additionally, astaxanthin is the only carotenoid that can cross the blood brain barrier [6], which can protect the blood brain barrier from damage caused by oxidation. In addition, astaxanthin shows other important biological activities, including anti-obesity [7], anti-tumor [8], anti-inflammatory [9], anti-atherosclerotic [10], and immune-boosting properties [11], among others.

Astaxanthin exists as two enantiomers $\left(3 R, 3^{\prime} R\right.$ and $\left.3 S, 3^{\prime} S\right)$ in a meso form $\left(3 S, 3^{\prime} R\right)$ because it has two stereo-genic carbon atoms at the $\mathrm{C} 3$ and $C 3^{\prime}$ positions [12]. P. rhodozyma astaxanthin is mainly the $\left(3 R, 3^{\prime} R\right)$ 
isomer [13], H. pluvialis astaxanthin is mainly the $\left(3 S, 3^{\prime} S\right)$ isomer [14], and the chemically synthesized astaxanthin has a stereoisomeric ratio of $1: 2: 1$ of the $\left(3 S, 3^{\prime} S\right),\left(3 S, 3^{\prime} R\right),\left(3 R, 3^{\prime} R\right)$ isomers $[13,15]$. Synthetic astaxanthin is widely used as an additive in fish feed, whereas naturally derived astaxanthin (mainly from P. rhodozyma and H. pluvialis) can be utilized in food and medicine $[6,16]$. Researchers have shown that the bioactivities of astaxanthin vary depending on its configuration [17], e.g., the potency of the chemical antioxidant activity is $\left(3 S, 3^{\prime} S\right)$-astaxanthin $>\left(3 R, 3^{\prime} R\right)$-astaxanthin $>$ $\left(3 S, 3^{\prime} R\right)$-astaxanthin $[13,18]$. In recent years, methods have been developed to distinguish astaxanthin stereoisomers. Three groups of rainbow trout were fed for 60 days of diets containing astaxanthin from three different sources. A characteristic distribution of astaxanthin stereoisomers was detected for each pigment source and such distribution were reproduced in the flesh of trout fed with that source [19]. Grewe et al. determined the configuration of astaxanthin derived from different microorganisms using a Chiralcel OD-RH column [20]. Subramanian et al. identified geometrical isomers of astaxanthin by Raman spectroscopy and UV-Vis absorption spectroscopy [21]. Wang et al. reported a direct and baseline separation method for all stereoisomers of all-trans-astaxanthin and other structurally-related carotenoids [15].The differences in the relative ratios of the configurational isomers of astaxanthin can be applied to distinguish aqua-cultured and wild salmon and identify astaxanthins derived from different sources [22]. A striking difference in the composition of astaxanthin optical isomers in Chlamydomonas nivalis was found to be concerned with geographically distinct regions with high-performance liquid chromatography (HPLC) methods [12]. However, former methods only studied the identification and qualitative analysis of the stereoisomers of a single source of astaxanthin. Astaxanthin from different sources possesses many optical isomers and each has different biological activities and economic value. In the market, the astaxanthins from different sources were possibly mixed as the color additive for salmon and incorrectly labeled in the content claims in pursuing profit ( $\$ 2500 \mathrm{USD} / \mathrm{kg}$, worldwide turnover of several hundred thousand $\mathrm{kg}$ per year [20]). It is required to identify the astaxanthin category from the mixture and quantify the astaxanthin of each source to justify the statements and claims, but identification of the sources and quantitative analysis of the concentration of each differently sourced astaxanthin in a mixture have not been reported.

In this study, we used HPLC data to establish a quantitative analysis model for the first time to determine the sources and concentrations of each astaxanthin component in a mixed sample. This study not only has important applications in the apportionment of astaxanthin mixtures but may also shed light on quantitative analysis of other sample mixtures with stereoisomers from different sources.

\section{Results and Discussion}

\subsection{Identification of Astaxanthin from Different Sources Using High-Performance Liquid Chromatography (HPLC)}

Three different astaxanthins, sourced from P. rhodozyma, H. pluvialis, and chemical synthesis, were analyzed by HPLC using a ZORBAX SB-C18 reversed-phase column (Figure 1A) and a chiral CHIRALPAK IC column (Figure 1B). The astaxanthins from different sources shared one absorbance peak at the same retention time of $13.667 \mathrm{~min}$ in the reversed-phase column, and no enantiomers could be separated (Figure 1A). The content of astaxanthin from different sources was almost the same. The three configurational isomers of astaxanthin could be separated in the CHIRALPAK IC column (Daicel Chiral Technologies Co., Ltd., Shanghai, China) (Figure 1B) in the eluting order of $\left(3 S, 3^{\prime} S\right)$, $\left(3 S, 3^{\prime} R\right)$, and $\left(3 R, 3^{\prime} R\right)$, which agrees with the results of Řezanka [12]. It can also be seen that astaxanthin from $P$. rhodozyma had configurations of $\left(3 R, 3^{\prime} R\right)$ and $\left(3 S, 3^{\prime} R\right)$. The astaxanthin from $H$. pluvialis showed a composition of the $\left(3 S, 3^{\prime} S\right)$ and $\left(3 S, 3^{\prime} R\right)$ enantiomers, and the synthetic astaxanthin contained $\left(3 S, 3^{\prime} S\right)$, $\left(3 S, 3^{\prime} R\right)$, and $\left(3 R, 3^{\prime} R\right)$ configurations. 


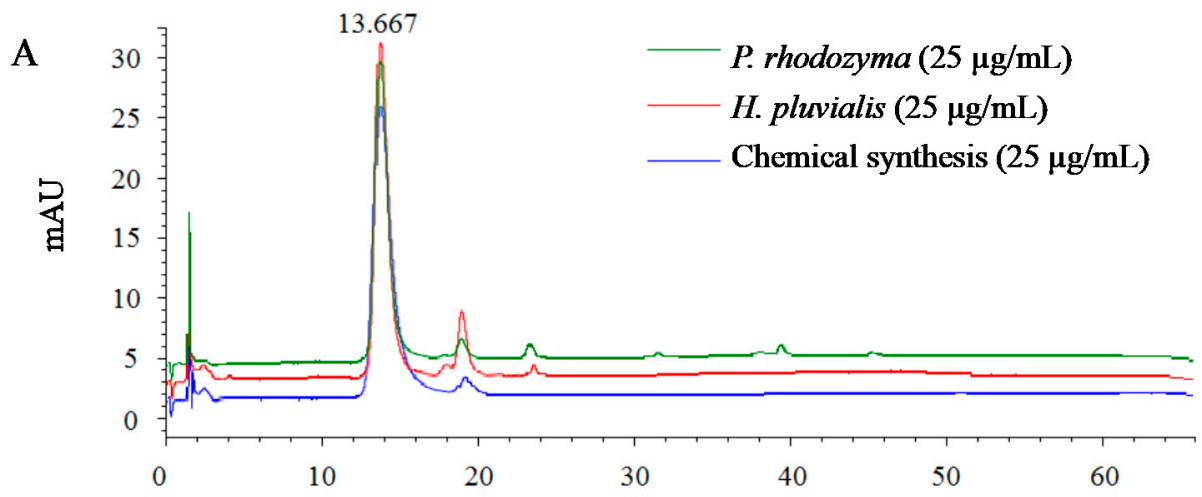

B

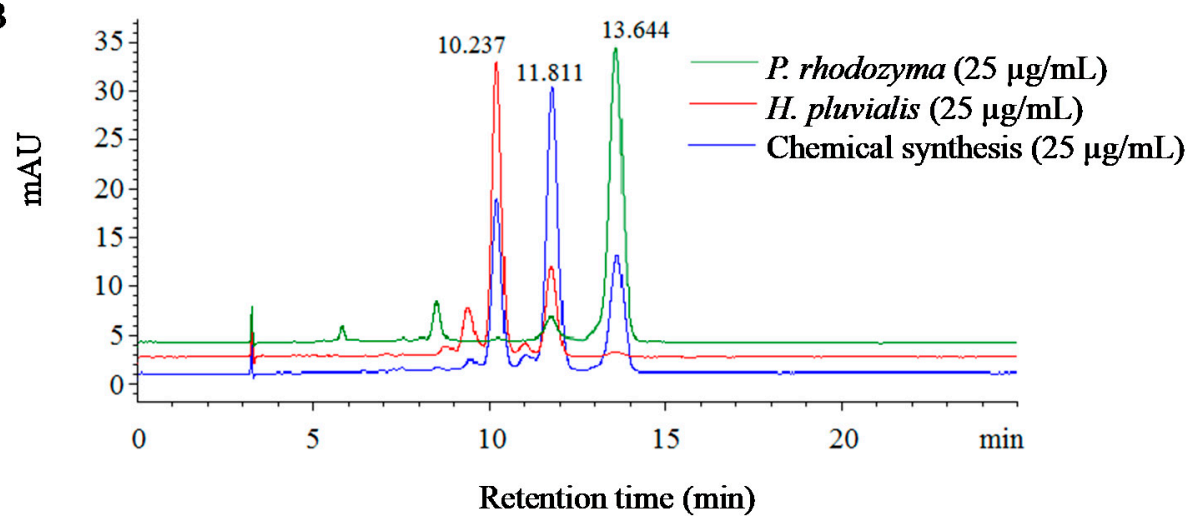

Figure 1. Separation of astaxanthin from P. rhodozyma, H. pluvialis, and chemical synthesis by high-performance liquid chromatography (HPLC) with ZORBAX SB-C18 (A) and CHIRALPAK IC (B) columns.

The peak areas of the enantiomers of astaxanthin from the three sources (Figure $1 \mathrm{~B})$ are shown in Table 1. P. rhodozyma astaxanthin was composed of dextral $\left(3 R, 3^{\prime} R\right)$ and racemic $\left(3 S, 3^{\prime} R\right)$ isomers at a ratio close to $15: 1$. H. pluvialis astaxanthin consisted of levo $\left(3 S, 3^{\prime} S\right)$ and racemic $\left(3 S, 3^{\prime} R\right)$ isomers at a ratio of $3: 1$. The synthetic astaxanthin contained the three levo $\left(3 S, 3^{\prime} S\right)$, racemic $\left(3 S, 3^{\prime} R\right)$ and dextral $\left(3 R, 3^{\prime} R\right)$ isomers at a ratio of $1: 2: 1$. The configurations of the synthetic astaxanthin and their ratio were in agreement with those reported by Rezanka [12]. The astaxanthin from P. rhodozyma was observed as having one more enantiomer, the $\left(3 S, 3^{\prime} R\right)$ enantiomer, than the former report [13]. Furthermore, a majority of the astaxanthin from $H$. pluvialis was $\left(3 S, 3^{\prime} S\right)$, which is consistent with the results of Sun et al. [14], but small amounts of $\left(3 S, 3^{\prime} R\right)$-astaxanthin was present in our separation.

Table 1. Peak area of the individual enantiomers of astaxanthin sourced from P. rhodozyma, H. pluvialis, and chemical synthesis.

\begin{tabular}{cccc}
\hline Isomer & $\begin{array}{c}\text { P. rhodozyma } \\
\text { (mAU*S) }\end{array}$ & $\begin{array}{c}\text { H. pluvialis } \\
\text { (mAU*S) }\end{array}$ & $\begin{array}{c}\text { Chemical Synthesis } \\
\text { (mAU*S) }\end{array}$ \\
\hline $3 S, 3^{\prime} S$ & - & 640.53 & 405.19 \\
$3 S, 3^{\prime} R$ & 55.87 & 222.55 & 828.27 \\
$3 R, 3^{\prime} R$ & 789.90 & - & 415.65 \\
\hline \multicolumn{4}{c}{ mAU*S represents peak area unit. }
\end{tabular}

The astaxanthin from one source possesses different isomers and one source of astaxanthin could be easily quantified by the standard curve established by the HPLC result, while the amount of each source astaxanthin from the mixture of different sources could not be directly identified from a standard curve due to part overlap of peaks between isomers from different sources. 


\subsection{Establishment of the Quantitative Analysis Model}

Although individual sources of astaxanthin consisted of different isomers with constant isomeric ratios, it was difficult for us to analyze the composition of a mixture of several-source astaxanthin and determine its various sources. To distinguish astaxanthin from several different sources and quantify every category, we established a quantitative analysis model based on the experimental results of HPLC. The model was built by the following two principles.

One principle was to establish the calibration curve of one stereoisomer of astaxanthin from a single source. The calibration curve reflects the relationship between the peak area of one stereoisomer and its concentration, which can be expressed as Equation (1).

$$
y_{m i}=a_{m i} x_{i}+b_{m i}
$$

where $y_{m i}$ is the peak area of one enantiomer from one source $(m=1,2$, or 3 , representing the number of enantiomers; $i=1,2 \ldots n$, representing the number of sources) and $x_{i}$ denotes the concentration of astaxanthin from one source.

The other principle was the additive property of the peak areas of an enantiomer, which was contributed to by all astaxanthin sources. The peak area of one stereoisomer in the mixed sample can be expressed as Equation (2).

$$
S_{m}=\sum_{i=1}^{n} y_{m i}
$$

For embodiment, we assumed that the mixture was composed of two substances with each having three stereoisomers at different ratios. The quantitative analysis model can be described by combining Equation (1) and Equation (2).

$$
\begin{aligned}
& S_{1}=a_{11} x_{1}+b_{11}+a_{12} x_{2}+b_{12} \\
& S_{2}=a_{21} x_{1}+b_{21}+a_{22} x_{2}+b_{22} \\
& S_{3}=a_{31} x_{1}+b_{31}+a_{32} x_{2}+b_{32}
\end{aligned}
$$

where the concentrations of substances from the two sources are $\mathrm{x}_{1}$ and $\mathrm{x}_{2}$, respectively. $S_{1}, S_{2}$, and $S_{3}$ represent the total peak areas of the three enantiomers, respectively, and $a_{m i}$ and $b_{m i}$ are the slope and intercept of the calibration curves of $y_{m i}$, respectively, for each enantiomer $(m=1,2,3$, representing the number of enantiomers and $i=1,2$, representing the number of sources).

Similarly, for the mixture composed of three different sources of astaxanthin with three stereoisomers at different ratios, the quantitative analysis model can be expressed as follows.

$$
\begin{aligned}
& S_{1}=a_{11} x_{1}+b_{11}+a_{12} x_{2}+b_{12}+a_{13} x_{3}+b_{13} \\
& S_{2}=a_{21} x_{2}+b_{21}+a_{22} x_{2}+b_{22}+a_{23} x_{3}+b_{23} \\
& S_{3}=a_{31} x_{1}+b_{31}+a_{32} x_{2}+b_{32}+a_{33} x_{3}+b_{33}
\end{aligned}
$$

where the concentrations of isomers from the three sources are $\mathrm{x}_{1}, \mathrm{x}_{2}$, and $\mathrm{x}_{3}$, respectively, and $S_{1}$, $S_{2}$, and $S_{3}$ represent the total peak areas of the three enantiomers in the mixed sample, respectively. The parameters $a_{m i}$ and $b_{m i}$ are the slope and intercept, respectively, which were obtained from the calibration curves of $y_{m i}(m=1,2,3$, representing the number of enantiomers and $i=1,2,3$, representing the number of sources).

Analogously, a mixture composed of $\mathrm{n}$ different sources of astaxanthin with three stereoisomers at different ratios could be applied to the analytical model with the following equations.

$$
\begin{aligned}
& S_{1}=a_{11} x_{1}+a_{12} x_{2}+\ldots+a_{1 n} x_{n}+k_{1} \\
& S_{2}=a_{21} x_{1}+a_{22} x_{2}+\ldots+a_{2 n} x_{n}+k_{2}
\end{aligned}
$$




$$
S_{3}=a_{31} x_{1}+a_{32} x_{2}+\ldots+a_{3 n} x_{n}+k_{3}
$$

where $k_{1}=b_{11}+b_{12}+\ldots+b_{1 n} ; k_{2}=b_{21}+b_{22}+\ldots+b_{2 n} ; k_{3}=b_{31}+b_{32}+\ldots+b_{3 n}$. The concentrations of substances from several different sources are $x_{1}, x_{2} \ldots x_{n}$, and $S_{1}, S_{2}$, and $S_{3}$ represent the total peak areas of the three enantiomers, respectively. The parameters $a_{m i}$ and $b_{m i}$ are the slope and intercept of the calibration curve of $y_{m i}(m=1,2,3$, representing the number of enantiomers and $i=1,2 \ldots n$, representing the number of sources). It should be mentioned that assuming three stereoisomers in all cases was mainly because only three stereoisomers at most could coexist in one source.

It can be seen from Equations (9)-(11) that the total peak area of the same stereoisomer from different sources of the same substance in a mixture and the calibration curves of different stereoisomers of each source were known. From this information, the sources and their respective concentrations in the mixture could be quantified.

Therefore, the model could be utilized to calculate the amount of each astaxanthin based on the experimental result of HPLC. This model could be expected to identify the astaxanthin category from the mixture of different sources and quantify the astaxanthin of each source, which can resolve the complicated quantitative problem due to part overlap among the isomers from different sources.

\subsection{Detection of Astaxanthin with the Quantitative Analysis Model}

Figure 2 shows the HPLC-separated result of P. rhodozyma, H. pluvialis, synthetic astaxanthin, and their mixture. The peaks of the mixture had retention times of $10.23 \mathrm{~min}, 11.81 \mathrm{~min}$, and 13.64 min, which were the same as the three enantiomers. However, we cannot qualify the composition of the mixture as judged by the retention time since the enantiomers in a single-source, two-source, or three-source astaxanthin mixture will produce the same retention times. It should be noted that the intensity ratio between isomers of single-source astaxanthin was constant, which include the dextral $\left(3 R, 3^{\prime} R\right)$ and racemic $\left(3 S, 3^{\prime} R\right)$ isomers at an intensity ratio of $15: 1$ in $P$. rhodozyma, the levo $\left(3 S, 3^{\prime} S\right)$ and racemic $\left(3 S, 3^{\prime} R\right)$ isomers at a ratio of $3: 1$ in $H$. pluvialis, and the levo $\left(3 S, 3^{\prime} S\right)$, racemic $\left(3 S, 3^{\prime} R\right)$ and dextral $\left(3 R, 3^{\prime} R\right)$ isomers at a ratio of 1:2:1 in synthetic astaxanthin. However, when two-source or three-source astaxanthin mixtures with different concentrations were analyzed (Figure 2), it was difficult for us to not only distinguish the astaxanthin from different sources through their relative signal ratios but also to directly quantify the isomers from each source.

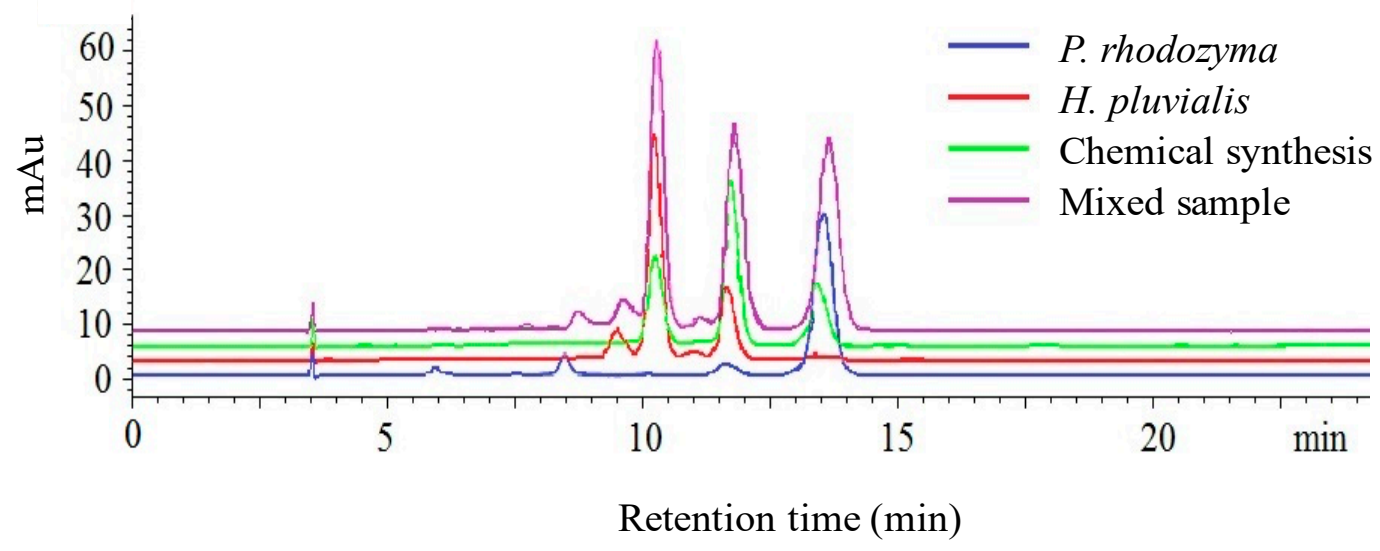

Figure 2. High-performance liquid chromatography (HPLC) analysis of P. rhodozyma, H. pluvialis, and synthetic astaxanthin at 25,30 , and $15 \mu \mathrm{g} / \mathrm{mL}$, respectively, and of their mixture.

However, according to the two steps of the mathematical model in the previous section, we can establish a quantitative analysis model for astaxanthin, from which the astaxanthin mixtures can be quantitatively analyzed, the composition can be determined, and the concentration of each source of astaxanthin can be achieved. 
First, the calibration curves of $\left(3 R, 3^{\prime} R\right)$ - and $\left(3 S, 3^{\prime} R\right)$-astaxanthin from $P$. rhodozyma, $\left(3 S, 3^{\prime} S\right)$ - and $\left(3 S, 3^{\prime} R\right)$-astaxanthin from $H$. pluvialis, and of $\left(3 S, 3^{\prime} S\right),\left(3 S, 3^{\prime} R\right)$ and $\left(3 R, 3^{\prime} R\right)$ from synthetic astaxanthin were established with the concentrations and peak areas, as shown in Figures S1-S3, Supplementary Materials. The linear relationships of all astaxanthin stereoisomers from the three sources were fairly good, and the correlation coefficients were all above 0.999 . The slope a and intercept $b$ of the calibration curves were obtained (Table 2), which were the required parameters for the model.

Table 2. Quantitative analysis model parameters for astaxanthin determination from P. rhodozyma, H. pluvialis, and chemical synthesis.

\begin{tabular}{ccccc}
\hline $\mathbf{S}$ & Calibration Curve & $\mathbf{a}$ & $\mathbf{b}$ & $\mathbf{k}$ \\
\hline \multirow{2}{*}{$\mathrm{S}_{1}=\mathrm{y}_{11}+\mathrm{y}_{12}$} & $\mathrm{y}_{11}=26.12 \mathrm{x}_{2}-5.6712$ & 26.12 & -5.6712 & \multirow{2}{*}{$\mathrm{k}_{1}=-4.0403$} \\
& $\mathrm{y}_{12}=16.595 \mathrm{x}_{3}+1.6309$ & 16.595 & 1.6309 & \\
\hline \multirow{2}{*}{$\mathrm{S}_{2}=\mathrm{y}_{21}+\mathrm{y}_{22}+\mathrm{y}_{23}$} & $\mathrm{y}_{21}=2.3151 \mathrm{x}_{1}-0.4045$ & 2.3151 & -0.4045 & \\
& $\mathrm{y}_{22}=9.4757 \mathrm{x}_{2}-1.489$ & 9.4757 & -1.489 & $\mathrm{k}_{2}=-2.3492$ \\
& $\mathrm{y}_{23}=34.198 \mathrm{x}_{3}-0.4557$ & 34.198 & -0.4557 & \\
\hline \multirow{2}{*}{$\mathrm{S}_{3}=\mathrm{y}_{31}+\mathrm{y}_{32}$} & $\mathrm{y}_{31}=32.543 \mathrm{x}_{1}-7.7618$ & 32.543 & -7.7618 & \multirow{2}{*}{$\mathrm{k}_{3}=-10.6925$} \\
\hline
\end{tabular}

Second, the quantitative analysis model for astaxanthin determination could be implemented when the parameters of $a, b$, and $k$ in the model described as Equations (9), (10), and (11) were defined. The parameter $\mathrm{k}$ can be determined as the sum of all $\mathrm{b}$ values. These parameters could be derived from the previously mentioned standard curves, as shown in Table 2. Then, the parameters a, b, and $k$ can be inputted in the quantitative analysis model (Equations (9)-(11)), and the quantitative analysis of astaxanthin can be achieved.

$$
\begin{gathered}
S_{1}=26.12 x_{2}+16.595 x_{3}-4.0403 \\
S_{2}=2.3151 x_{1}+9.4757 x_{2}+34.198 x_{3}-2.3492 \\
S_{3}=32.543 x_{1}+17.259 x_{3}-10.6925
\end{gathered}
$$

where $x_{1}, x_{2}$, and $x_{3}$ represent the concentrations of $P$. rhodozyma, H. pluvialis, and synthetic astaxanthin, respectively. $S_{1}, S_{2}$, and $S_{3}$ represent the total peak areas of $\left(3 S, 3^{\prime} S\right)-,\left(3 S, 3^{\prime} R\right)-$, and $\left(3 R, 3^{\prime} R\right)$-astaxanthin, as shown in the HPLC spectra.

Lastly, the sources of astaxanthin and their concentrations could be determined when the peak areas obtained experimentally were put into the quantitative model (Equations (12), (13), and (14)), and the three-dimensional first-order equations of the model were solved.

This model was suitable for the quantitative analysis of a mixture of astaxanthin from several different sources with a complex sample due to several isomers being present in each source. Related reports in the literature were all aimed at the quantitative analysis of astaxanthin from one source. For example, Turujman et al. used liquid chromatography to quantify synthetic astaxanthin, which is a pigmentation additive in salmon [22], based on the difference in the relative proportions of astaxanthin isomers. Dissing et al. established a partial least square regression (PLSR) model to predict the concentration of astaxanthin in rainbow trout slices [23].

\subsection{Verification of the Quantitative Analysis Model}

When the mixture of P. rhodozyma, H. pluvialis, and synthetic astaxanthin were separated by chromatography, the different isomers were separated, and the identical isomers from each source overlapped, which leads to the overall peak areas of each stereoisomer, with $S_{1}, S_{2}$, and $S_{3}$ denoting $\left(3 S, 3^{\prime} S\right)-,\left(3 S, 3^{\prime} R\right)-$, and $\left(3 R, 3^{\prime} R\right)$-astaxanthin, respectively. The concentration of each astaxanthin source could be obtained by putting the value of the above three peak areas into the model for solving the three-dimensional Equations (12), (13), and (14). The recovery rate, namely, the calculated concentration 
compared with the amount of astaxanthin added from each source for the experiments, was analyzed to verify the accuracy of the above model.

Table 3 shows the different concentration ratios of $P$. rhodozyma, $H$. pluvialis, and synthetic astaxanthin, the peak areas $S_{1}, S_{2}$, and $S_{3}$ of various isomers obtained from the HPLC spectra, and the calculated concentrations of three astaxanthins, $x_{1}, x_{2}$, and $x_{3}$, by using the quantitative models. Figure 3 shows the recovery rate obtained by the model calculation when the three sources of astaxanthin were mixed in different proportions. When the concentration ratio of P. rhodozyma, H. pluvialis, and synthetic astaxanthin was 1:1:1, namely, the concentration of astaxanthin from all three sources was $25 \mu \mathrm{g} / \mathrm{mL}$, the astaxanthin concentrations from each source were calculated to be 23.56, 24.92, and $26.35 \mu \mathrm{g} / \mathrm{mL}$, respectively, according to the quantitative analysis model. The recovery rate was $94.2 \%$. When the ratio was 1.0:0.2:0.2, namely, the three astaxanthin sources were at 25,5 , and $5 \mu \mathrm{g} / \mathrm{mL}$, respectively, the concentrations of astaxanthin from the three sources were calculated to be $24.15,5.23$, and $4.96 \mu \mathrm{g} / \mathrm{mL}$, respectively, by using the quantitative analysis model, and the recovery rate was $96.6 \%$. When the concentration ratio was 1.0:1.5:0.5, namely, the three sources of astaxanthin were at 50,75 , and $25 \mu \mathrm{g} / \mathrm{mL}$, respectively, the concentrations of astaxanthin from the three sources were determined to be $51.78,74.55$, and $29.27 \mu \mathrm{g} / \mathrm{mL}$, respectively, by using the model, and the recovery rate reached $103.6 \%$. When the concentration ratio of astaxanthin from the three sources was 1:3:4, i.e., at concentrations of 25,75 , and $100 \mu \mathrm{g} / \mathrm{mL}$, respectively, the calculated concentrations of astaxanthin were $25.53,75.03$, and $105.52 \mu \mathrm{g} / \mathrm{mL}$, respectively. The recovery rate was $102.1 \%$.

Table 3. Calculation and verification of the quantitative analysis model of mixed astaxanthin.

\begin{tabular}{|c|c|c|c|c|c|}
\hline $\begin{array}{l}\text { Actual Concentration } \\
\qquad(\mu \mathrm{g} / \mathrm{mL})\end{array}$ & $\begin{array}{c}\mathrm{S}_{1} \\
\left(\mathrm{mAU} \mathbf{U}^{*}\right)\end{array}$ & $\begin{array}{c}\mathrm{S}_{2} \\
\left(\mathrm{mAU} U^{*}\right)\end{array}$ & $\begin{array}{c}\mathrm{S}_{3} \\
\left(\mathrm{mAU} U^{*}\right)\end{array}$ & $\begin{array}{l}\text { Calculated Concentration } \\
\qquad(\mu \mathrm{g} / \mathrm{mL})\end{array}$ & $\begin{array}{c}\text { Recovery Rate } \\
(\%)\end{array}$ \\
\hline $25 x_{1}+5 x_{2}+5 x_{3}$ & $215.80 \pm 11.16$ & $272.68 \pm 9.21$ & $861.04 \pm 69.41$ & $24.15 x_{1}+5.23 x_{2}+4.96 x_{3}$ & 96.6 \\
\hline $25 x_{1}+25 x_{2}+25 x_{3}$ & $1084.81 \pm 12.72$ & $1189.62 \pm 32.78$ & $1211.06 \pm 41.44$ & $23.56 x_{1}+24.92 x_{2}+26.35 x_{3}$ & 94.2 \\
\hline $10 x_{1}+25 x_{2}+10 x_{3}$ & $804.46 \pm 16.58$ & $601.49 \pm 15.88$ & $472.68 \pm 15.82$ & $9.41 x_{1}+24.41 x_{2}+10.25 x_{3}$ & 94.1 \\
\hline $30 x_{1}+25 x_{2}+15 x_{3}$ & $879.53 \pm 15.09$ & $818.29 \pm 15.26$ & $1174.93 \pm 43.63$ & $28.24 x_{1}+23.99 x_{2}+15.44 x_{3}$ & 94.1 \\
\hline $50 x_{1}+75 x_{2}+25 x_{3}$ & $2429.42 \pm 49.13$ & $1825.07 \pm 7.79$ & $2179.89 \pm 19.12$ & $51.78 x_{1}+74.55 x_{2}+29.27 x_{3}$ & 103.6 \\
\hline
\end{tabular}

$\mathrm{mAU} * \mathrm{~S}$ represents the peak area unit.

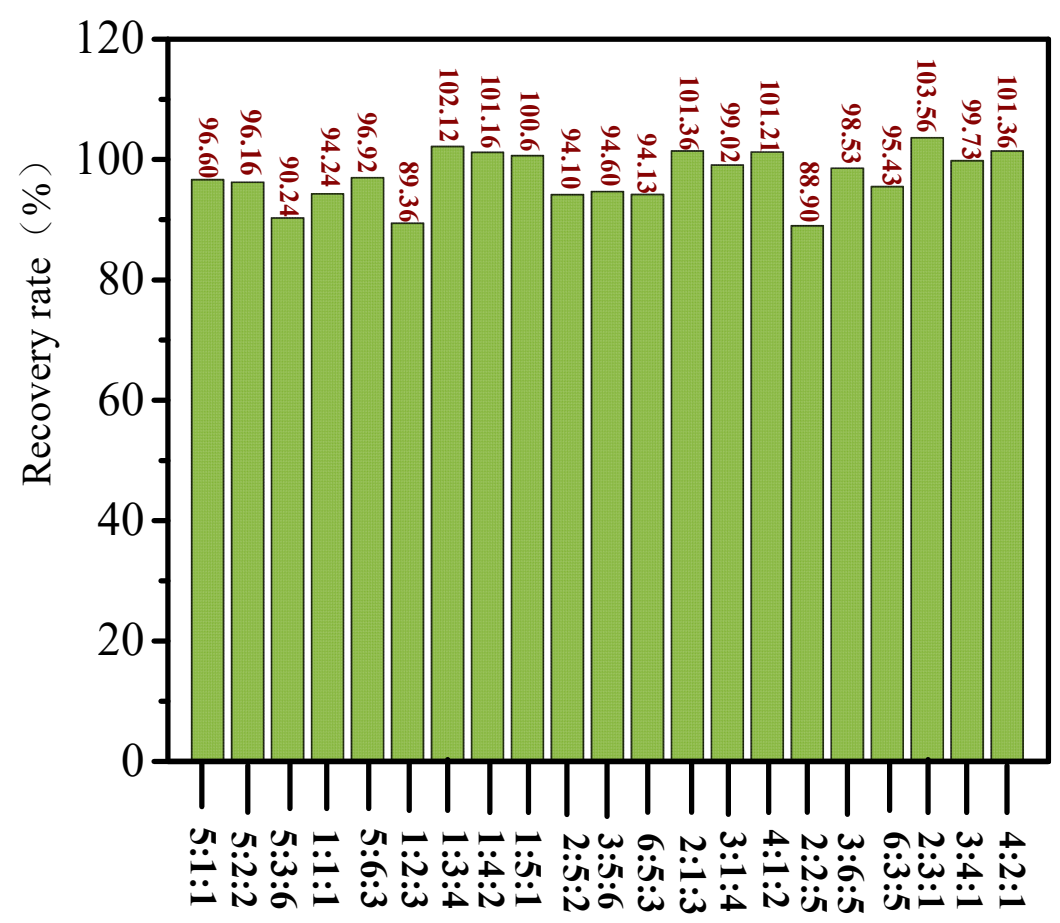

Figure 3. The recovery rate of astaxanthin from P. rhodozyma at different concentration ratios. 
When the astaxanthin from the three sources was mixed at different ratios, as shown in Table 3, the deviation between the calculated concentration and the actual concentration ranged from 0 to $7 \mu \mathrm{g} / \mathrm{mL}$, and the recovery rate was between $88.90 \%$ and $103.56 \%$ (Figure 3 ). This indicated that the quantitative analysis model of astaxanthin was feasible and reliable, which could be utilized to identify the astaxanthin category and quantify the astaxanthin of each source from different sources and resolve the complicated quantitative problem of the isomers from different sources.

This model can not only be applied to the quantitative analysis of astaxanthin but also provide a new pathway for the quantitative analysis of mixtures of other natural products from different sources with each source having different stereoisomer ratios. It should also be noted that the peak areas of astaxanthin in the quantitative analysis model were related to the precision of the method. The analytical range of astaxanthin in the chromatographic column was 5 to $100 \mu \mathrm{g} / \mathrm{mL}$, so the analytical range of the quantitative model was 5 to $100 \mu \mathrm{g} / \mathrm{mL}$.

\section{Experimental}

\subsection{Materials and Reagents}

Synthetic astaxanthin (USP, 100\% pure) was purchased from Sigma-Aldrich (St. Louis, MO, USA).Astaxanthin from P. rhodozyma and H. pluvialis were obtained from our laboratory with purities of $100 \%$ and $95.6 \%$ (calculated by peak area normalization) [24,25], respectively. They were all stored at $-20{ }^{\circ} \mathrm{C}$. Hexane, acetonitrile, tert-butyl-methyl-ether, 2-propanol, and methanol were of a chromatographic grade and were purchased from Sigma-Aldrich. Dichloromethane was of an analytical grade (Sinopharm Chemical Reagent Co., Ltd., Shanghai, China).

\subsection{Instrumentation}

Analysis was carried out using an Agilent 1260 infinity quaternary liquid chromatograph (Agilent Technologies Deutschland $\mathrm{GmbH}$, Böblingen, Germany) equipped with an auto injector, an online vacuum degasser, a G1311B/C quaternary pump, a G1329B autosampler, a G1330B thermostat, a G1316B thermostatted column compartment, and a G1314F variable wavelength detector (VWD). The columns applied in this work were a CHIRALPAK IC column $(250 \mathrm{~mm} \times 4.6 \mathrm{~mm}$, I.D., $5 \mu \mathrm{m}$, Daicel Chiral Technologies Co., Ltd., Shanghai, China) and a ZORBAX SB-C18column $(100 \mathrm{~mm} \times 2.1 \mathrm{~mm}$, I.D., $3.5 \mu \mathrm{m}$, Agilent Technologies, USA).

\subsection{HPLC Analysis}

Identification of the three different sources of astaxanthin were analyzed by HPLC with solvent system I consisting of ultrapure water (mobile phase A) and methanol (mobile phase B). The separation was performed on a ZORBAX SB-C18 column at a flow rate of $0.2 \mathrm{~mL} / \mathrm{min}$. The column temperature was $35^{\circ} \mathrm{C}$, the injection volume was $5.0 \mu \mathrm{L}$, and the detection wavelength was $474 \mathrm{~nm}$. Gradient elution conditions are shown as follows: $85 \%$ to $100 \%$ mobile phase B in mobile phase A in the first $40 \mathrm{~min}, 100 \%$ mobile phase B from 40 to $58 \mathrm{~min}$, and $100 \%$ to $85 \%$ mobile phase B in mobile phase A from 58 to $66 \mathrm{~min}$.

The three different sources of configurational isomers of astaxanthin were analyzed by HPLC with solvent system II consisting of acetonitrile (mobile phase C) and tert-butyl-methyl-ether (mobile phase D). Isocratic elution conditions were $0-25 \mathrm{~min}, 60 \% \mathrm{C}$ and $40 \% \mathrm{D}$. The separation was performed on a CHIRALPAK IC column at a flow rate of $1 \mathrm{~mL} / \mathrm{min}$. The column temperature was $25^{\circ} \mathrm{C}$, the injection volume was $10 \mu \mathrm{L}$, and the detection wavelength was $476 \mathrm{~nm}$.

\subsection{Sample Preparation}

Stock solutions of $300 \mu \mathrm{g} / \mathrm{mL}$ astaxanthin were prepared by dissolving $0.003 \mathrm{~g}$ three-source astaxanthin in acetonitrile and were immediately diluted to $225,150,90,75,45,30$, and $15 \mu \mathrm{g} / \mathrm{mL}$ prior to use. The three-source astaxanthin sample solutions were mixed at a certain ratio to obtain the 
mixture concentration shown in Table 3. Then, the mixture was filtered through a $0.22-\mu \mathrm{m}$ microporous membrane. Lastly, the mixtures were measured by HPLC analysis in triplicate.

\subsection{Statistical Analysis}

All analyses were performed and evaluated in triplicate. Statistical analyses were performed using Microsoft Office Excel 2013. The results are expressed as the mean \pm SD.

\section{Conclusions}

This study successfully established a quantitative analysis model that could be used to determine the sources and concentrations of each source of astaxanthin in mixed astaxanthin samples. The quantitative analysis model was verified, and the results showed that the deviation between the calculated concentration and the actual concentration ranged from 0 to $7 \mu \mathrm{g} / \mathrm{mL}$. The recovery rate was between $88.90 \%$ and $103.56 \%$. This indicated that the quantitative analysis model of astaxanthin was feasible and reliable. This study cannot only be applied in the analysis of mixed astaxanthin but also may castlight on quantitative analysis of other sample mixtures with stereoisomers from different sources.

Supplementary Materials: The following are available online. Figure S1: The calibration curves of $\left(3 R, 3^{\prime} R\right)$-astaxanthin (A) and ( $\left.3 \mathrm{~S}, 3^{\prime} \mathrm{R}\right)$-astaxanthin (B) from P. rhodozyma. Figure S2: The calibration curves of $\left(3 S, 3^{\prime} S\right)$-astaxanthin $(A)$ and $\left(3 S, 3^{\prime} R\right)$-astaxanthin (B) from H. pluvialis. Figure S3: The calibration curves of $\left(3 S, 3^{\prime} R\right)$-astaxanthin $(\mathrm{A}),\left(3 R, 3^{\prime} R\right)$-astaxanthin $(\mathrm{B})$ and $\left(3 S, 3^{\prime} S\right)$-astaxanthin $(\mathrm{C})$ from synthetic astaxanthin.

Author Contributions: Conceptualization, X.D. and Q.Z. Methodology, H.N. and M.B. Formal Analysis, X.W. and M.B. Investigation, X.D. and M.B. Resources, Q.Z. Writing-Original Draft Preparation, X.D., M.B., and Q.Z. Writing-Review \&Editing, S.L., G.H., and F.C. Project Administration, X.D. All authors have read and agreed to the published version of the manuscript.

Funding: The key project of science and technology department of Fujian province (2018N0019) and the National Natural Science Foundation of China (31501448) supported this work.

Conflicts of Interest: The authors declare no conflicts of interest.

\section{References}

1. Ambati, R.R.; Phang, S.M.; Ravi, S.; Aswathanarayan, R.G. Astaxanthin: sources, extraction, stability, biological activities and its commercial applications-A review. Mar. Drugs 2014, 12, 128-152. [CrossRef] [PubMed]

2. Boonyaratpalin, M.; Thongrod, S.; Supamattaya, K.; Britton, G.; Schlipalius, L.E. Effects of $\beta$-carotene source, Dunaliella salina, and astaxanthin on pigmentation, growth, survival and health of Penaeus monodon. Aquac. Res. 2001, 32, 182-190. [CrossRef]

3. Liu, X.J.; Luo, Q.X.; Rakariyatham, K.; Cao, Y. Antioxidation and anti-ageing activities of different stereoisomeric astaxanthin in vitro and in vivo. J. Funct. Foods 2016, 25, 50-61. [CrossRef]

4. Kindlund, P.J. Astaxanthin. Nutrafoods 2011, 10, 27-31. [CrossRef]

5. Naguib, Y.M.A. Antioxidant activities of astaxanthin and related carotenoids. J. Agric. Food Chem. 2000, 48, 1150-1154. [CrossRef]

6. Goswami, G.; Chaudhuri, S.; Dutta, D. The present perspective of astaxanthin with reference to biosynthesis and pharmacological importance. World J. Microb. Biot. 2010, 26, 1925-1939. [CrossRef]

7. Du, X.P.; Bai, M.L.; Huang, Y.; Jiang, Z.D.; Chen, F.; Ni, H.; Li, Q.B. Inhibitory effect of astaxanthin on pancreatic lipase with inhibition kinetics integrating molecular docking simulation. J. Funct. Foods 2018, 48, 551-557. [CrossRef]

8. Zhang, L.; Wang, H.D. Multiple mechanisms of anti-cancer effects exerted by astaxanthin. Mar. Drugs 2015, 13, 4310-4330. [CrossRef]

9. Ying, C.J.; Zhang, F.; Zhou, X.Y.; Hu, X.T.; Chen, J.; Wen, X.R.; Sun, Y.; Zheng, K.Y.; Tang, R.X.; Song, Y.J. Anti-inflammatory effect of astaxanthin on the sickness behavior induced by diabetes mellitus. Cell Mol. Neurobiol. 2015, 35, 1-11. [CrossRef] 
10. Kishimoto, Y.; Yoshida, H.; Kondo, K. Potential anti-atherosclerotic properties of astaxanthin. Mar. Drugs 2016, 14, 35. [CrossRef]

11. Cheng, C.H.; Guo, Z.X.; Ye, C.X.; Wang, A.L. Effect of dietary astaxanthin on the growth performance, non-specific immunity, and antioxidant capacity of pufferfish (Takifuguobscurus) under high temperature stress. Fish Physiol. Biochem. 2017, 44, 209-218. [CrossRef] [PubMed]

12. Ǩezanka, T.; Nedbalová, L.; Kolouchová, I.; Sigler, K. LC-MS/APCI identification of glucoside esters and diesters of astaxanthin from the snow alga Chlamydomonas nivalis including their optical stereoisomers. Phytochemistry 2013, 88, 34-42. [CrossRef] [PubMed]

13. Liu, X.J.; Song, M.Y.; Gao, Z.L.; Cai, X.K.; Dixon, W.; Chen, X.F.; Cao, Y.; Xiao, H. Stereoisomers of astaxanthin inhibit human colon cancer cell growth by inducing G2/M cell cycle arrest and apoptosis. J. Agric. Food Chem. 2016, 64, 1-10. [CrossRef] [PubMed]

14. Sun, W.H.; Hong, L.; Zhai, Y.X.; Gao, L.M.; Leng, K.L.; Xing, L.H. Separation, purification, and identification of (3S, 3'S)-trans-astaxanthin from Haematococcus pluvialis. Sep. Sci. Technol. 2015, 50, 1377-1383. [CrossRef]

15. Wang, C.L.; Armstrong, D.W.; Chang, C.D. Rapid baseline separation of enantiomers and a mesoform of all-trans-astaxanthin, 13-cis-astaxanthin, adonirubin, and adonixanthin in standards and commercial supplements. J. Chromatogr. A 2008, 1194, 172-177. [CrossRef] [PubMed]

16. Guerin, M.; Huntley, M.E.; Olaizola, M. Haematococcus astaxanthin: Applications for human health and nutrition. Trends Biotechnol. 2003, 21, 210-216. [CrossRef]

17. Pérez-López, P.; González-García, S.; Jeffryes, C.; Agathos, S.N.; McHugh, E.; Walsh, D.; Murray, P.; Moane, S.; Feijoo, G.; Moreira, M.T. Life cycle assessment of the production of the red antioxidant carotenoid astaxanthin by microalgae: From lab to pilot scale. J. Clean. Prod. 2014, 64, 332-344. [CrossRef]

18. Liu, X.J.; Chen, X.F.; Liu, H.; Cao, Y. Antioxidation and anti-aging activities of astaxanthin geometrical isomers and molecular mechanism involved in Caenorhabditis elegans. J. Funct. Foods 2018, 44, 127-136. [CrossRef]

19. Moretti, V.M.; Mentasti, T.; Bellagamba, F.; Luzzana, U.; Caprino, F.; Turchini, G.M.; Giani, I.; Valfrè, F. Determination of astaxanthin stereoisomers and colour attributes in flesh of rainbow trout (Oncorhynchus mykiss) as a tool to distinguish the dietary pigmentation source. Food Addit. Contam. 2006, 23, 1056-1063. [CrossRef]

20. Grewe, C.; Menge, S.; Griehl, C. Enantioselective separation of all- E -astaxanthin and its determination in microbial sources. J. Chromatogr. A 2007, 1166, 97-100. [CrossRef]

21. Subramanian, B.; Tchoukanova, N.; Djaoued, Y.; Pelletier, C.; Ferron, M.; Robichaud, J. Investigations on the geometrical isomers of astaxanthin: Raman spectroscopy of conjugated polyene chain with electronic and mechanical confinement. J. Raman Spectrosc. 2014, 45, 299-304. [CrossRef]

22. Turujman, S.A.; Wamer, W.G.; Wei, R.R.; Albert, R.H. Rapid liquid chromatographic method to distinguish wild salmon from aquacultured salmon fed synthetic astaxanthin. J. AOAC Int. 1997, 80, 622-632. [PubMed]

23. Dissing, B.S.; Nielsen, M.E.; Ersbøll, B.K.; Frosch, S. Multispectral imaging for determination of astaxanthin concentration in salmonids. PLOS ONE 2011, 6, 1-8. [CrossRef] [PubMed]

24. Bai, M.L.; Chen, Y.H.; Huang, Y.; Huang, G.L.; Yang, Y.F.; Du, X.P. Separation of carotenoids from Phaffia rhodozyma by HSCCC and silica gel column chromatography. Food Industry 2019, 40, 143-147.

25. Bai, M.L.; Wang, H.Q.; Wu, L.; Chen, Y.H.; Huang, G.L.; Du, X.P. Optimization and separation of astaxanthin from Haematococcus pluvialis by High-Speed Counter-Current Chromatography. Acta Laser Biology Sinica 2018, 27, 460-466.

Sample Availability: Samples of the compounds are available from the authors. 